\title{
Screen Memory
}

\author{
Lindsey A. Freeman • Benjamin Nienass • \\ Laliv Melamed
}

Published online: 7 February 2013

(C) Springer Science+Business Media New York 2013

The traumas and catastrophes of modernity uprooted and obliterated lands, cultures, and people; and in the wake of these disasters, mnemonic practices and mnemonic communities were disrupted, dismembered, and sometimes destroyed. In response to the assaults on memory, those in the social sciences and the humanities have tried to make sense of the effects of dramatic change and mass trauma on mnemonic communities. Much of the recent scholarship on social memory centers on the globalization of memory - the tendency of some memories to gain widespread purchase transnationally and transculturally-especially those of traumatic events, such as colonial pasts, genocides, state violence, and the Holocaust. An effect of the globalization of memory is the primacy of certain memories over others; popular theoretical paradigms have emerged in recent years to broaden our understanding of the social memory of these events, such as the "politics of regret" by Jeffrey Olick (2007), "mimetic memories" by Kathleen Stewart (1996), "regimes of memory" by Susannah Radstone and Katharine Hodgkin (2003), and "multi-directional memory" by Michael Rothberg (2008) among others. We engage with these concepts and theories, but do so in order to reinvigorate an older concept of memory theory, articulated first by Sigmund Freud at the turn of the twentieth century: screen memory.

Here, we argue for the concept of screen memory as a way to both conceptualize and trouble contemporary notions of social memory. In the past, screen memory has been viewed and employed rather one-dimensionally as a memory that obscures other memories by blocking or replacing them (Freud 1901). Freud argued that memories from childhood may be incorrectly recalled or recalled in a way that magnifies or

\footnotetext{
L. A. Freeman $(\bowtie)$

Departments of Sociology \& Historical Studies, New School for Social Research, New York, NY, USA e-mail: freeL374@newschool.edu

B. Nienass

Department of Political Science, Stern College for Women, Yeshiva University, New York, NY, USA e-mail: nienass@yu.edu

L. Melamed

Department of Cinema Studies, New York University, New York, NY, USA

e-mail: lm1539@nyu.edu
} 
minimizes their importance, thereby masking another memory of deep emotional significance. We want to move away from thinking of screen memory as simply something that obscures. We see in the concept of screen memory a bracketing mechanism that draws attention to the complexities of social memory, as it simultaneously produces and interrogates knowledge about the past.

In examining screen memory, the authors of this special issue attempt to untangle claims to the past in challenging environments where evidence is sometimes lacking, sometimes ahistorical, sometimes inauthentic, and often contested. We also question what the potential stakes for highjacked, relocated, and even faux memories might be. We argue that in some cases, even deliberately counterfeited memories could enable historical truths to emerge, strengthen remembering communities, or, even produce new ones. As the "careering juggernaut" of modernity has swept away some traditional practices and communities, it has presented new possibilities for connecting, and new inclusive spaces for memories, where opposing stories about the past can converge and commingle, rather than simply block each other out (Giddens 1990, p.53). But we are cautious not to be too utopian when thinking about the constitutive powers of screened memories, and we understand that within this practice many dangers lurk, including further displacement of past truths, the appropriation and distortion of memory, nostalgic longing, or historical theft. Still, in the spirit of Walter Benjamin (2003), we see possibility in the fragments of the past, the potential for rediscovery and even redemption of forgotten memories, as well as the possibility for counter-memories to emerge through new mnemonic practices.

With Rothberg (2008), we read the notion of screen memory not merely as a substitution, but as a temporary "displacement" in which the forgotten memory is "subject to recall." Consequently, the relationship between memories is best understood as "multi-directional" in the sense that a covered memory, even if altered and reexamined in the process of interacting with other memories, can speak back. This movement of memories and memory practices is an example of the "disembedding mechanisms," that characterize modernity, which "lift out social activity from localized contexts," thereby "reorganizing social relations across large time-space distances" (Giddens 1990, p. 53). Reading Rothberg reading Freud we understand the displacement of memory as displacement as well as re-placement of memory, disembedding as well as reembedding: memory re-emerges in seemingly unrelated geographical locations, historical periods, and material objects.

With "multidirectional" screened memories, mnemonic communities might not be those initially expected, as in the case of the revival of Jewish heritage festivals where diverse populations in Poland, Spain, and Russia - most of which have no first-person or familial ties to Jewish communities_- "remember" Jewish heritage (Salamensky 2013). What sparks the memory of an absent or relocated group in any location is a complicated and varied process, which may have certain practices and in aesthetics common, but always, has a local character. We argue that space and place should be seen here not as mere metaphors, but rather as key elements in the construction and continuation of memory and memory cultures on the one hand, and the void, deconstruction, relocation, or dissolution of remembering groups and realms of memory, on the other.

Applying Freudian concepts to collective practices often seems to serve a purely metaphorical function, igniting our imagination about potentially concealed social and cultural processes but leaving us with little to work with once we start examining these processes in more detail. But with Olick (2008, p. 5), we envision the strong possibility that Freudian insights can help us develop an outlook that "theorize(s) 'unconscious' dimensions of memory at a level that supersedes that of the individual" and transcends views of memory as simply shaped by current interests. Only such a view will allow us to address the 
unintended consequences of memory in its collective forms, the "ghosts" that Derrida (1996) described in Archive Fever.

Employing the concept of screen memory, we not only hope to resist simplistic assumptions about "mnemonic rationalism and identitarian voluntarism" (Olick 2008, p. 5), but also to go beyond ideas of social memory as intergenerational communication by including a strong focus on the material inscription of transgenerational memory. The focus on the cultural aspect of memory (Assman 1995) - memory transferred through artifacts, objects, texts, and seemingly unrelated social practices - is our starting point to examine the "ciphered archive of lost memories" (Olick 2008, p.16) that lets us envision a possibility for the forgotten past to speak back in the most unexpected and seemingly unrelated locations. The relationship implied by the concept of screen memory, both in Freud's original term and in Rothberg's extension, is thus not inevitably defined by the logic of competition, but can in fact have unexpected productive and creative consequences. It is furthermore best viewed as a multilayered relationship, in the sense that the chain of association that produces the screen can incorporate several memories, material objects, and temporal relationships at once.

With this conceptual apparatus applied to the rich case studies in this special issue we seek to address the following questions: What happens when cultural festivals, museums, urban memorial projects, material objects, supranational governing bodies, or films evoke multidirectional memories? How do transnational practices of commemoration and documentation serve as screens that allow for the presence of some local and national pasts while rendering others invisible? How do multidirectional memories affect the "politics of regret," as defined by Olick (2007), where nations are judged not on their present and future plans, but instead on their ability to atone for the past, not just locally, but globally? What kinds of issues emerge for local recognition, as compared to transnational attention? How do we sift through multiple and conflicting accounts, discoveries, and material traces of the past in an age where forensic science, digital media, and the study of social memory both illuminate and complicate evidence of the past? By addressing these questions in specific case studies that cover a wide variety of historical events and geographical terrains across Europe, or involve European actors, including - the question of a European ethics of memory, the memory landscape of Berlin, Jewish heritage festivals in places without Jewish populations, forensic evidence versus forensic absence in Kosovo, the role of Denmark in the transatlantic slave trade, and the German propaganda films of the Polish ghetto-this special issue offers new ways to understand how memory, counter-memory, and "faux memory" cultures intersect in both local and international contexts, often in unexpected or unusual ways. We seek here not to provide definitive answers, but to open up the field of study in productive ways, by suggesting new models to think with. The concept of the screen strikes us as a particularly fruitful starting point, as it encompasses notions of projection, division, and concealment as well as examination and movability and consequently allows us to capture both the competitive/political and the critical dimensions of memory encounters.

\section{Politics of Regret}

A "politics of regret" (Olick 2007) has helped to define the contemporary mnemonic climate, where atoning for a negative past, and demonstrating a working through that past, through truth and reconciliation commissions, public apologies, and expressions of regret, have come to be seen as essential ethical mnemonic practices and sources of political legitimacy. While the "politics of regret" can undoubtedly have positive social and political consequences, not least in fostering "post-nationalistic" (Müller 2007) political cultures, we 
want to argue that regretful memory politics can also function as a screen with which to distract from current responsibilities both by projecting an image of a temporal other and a spatial other and by projecting an image of a better present and future.

Nienass (2013), for example, examines how far discourses about specific memory practices associated with the politics of regret have played a role in discussions about a postnational European identity. He shows the interplay between particular imaginaries and transnational memory standards by laying out how these standards provide a source for a new positive self-image, paradoxically one that incorporates rather than refuses the stigma of a perpetrator identity. Along with the "politics of regret", Sodaro (2013) introduces another set of memory practices that have proliferated in the last several decades, the "politics of nostalgia." In her study of the Jewish Museum in Berlin, she shows how the museum functions, in part, as a screen, whereby an idealized Jewish past is projected for visitors to consume. This projection of a time of multicultural bliss not only threatens to minimize an atrocious historical past, but it also risks carrying that sentiment into the present, eliding current tensions in Germany around issues of multiculturalism. Nostalgic politics can also be seen in Andersen's article on public memories of slavery and colonialism in Denmark. For much of the twentieth century, official narratives in Denmark exhibited romanticized views of peaceful relations between colonizer and slave and versions of colonial conquest as the "white man's burden". Faced with mounting pressure from the former colonies to revise their interpretation of the colonial past and to engage in practices associated with the "politics of regret", most notably a public apology, political actors across the political spectrum revised their narratives without fully giving up on some of the nostalgic tropes.

Throughout these articles, there is a pugilistic thread where regret and nostalgia engage in a battle over memory. While a politics of regret can come to be seen not only as the expression of the negative emotion of regret, but also of the positive emotion of (societal) maturity which rests on the acceptance of accountability (of one's forbearers), the politics of nostalgia is potentially more dangerous, leaving us with a history devoid of guilt (Kammen 1991, p. 668). This tension is perhaps no more alive than in the memoryscape of Berlin (Bach 2013; Sodaro 2013), where the battles over what to remember and how to do so keep the city in a constant wrestle with its past. Bach shows how the urban terrain of the city is sewn and unsewn by the Wall, where both the space of the city and its trajectory through time is bifurcated.

\section{Mimetic Memories}

As memories pile, it becomes possible to see how cultures privilege not only memory, but what Kathleen Stewart (1996) has called "mimetic memories," memories that follow similar tropes, narratives, and aesthetics. Screen memory - in our account-is thus not only concerned with memories concealed by projections of other pasts, but also with memories brought to light or reexamined by their connections, or perceived similarities, to other memories or traumas. These memories need not be exact copies, or even historically accurate, as can be seen in the mimetic memories examined in Salamensky's comparative study (2013) of the performance of "Jewface" and "Jewfacade." Salamensky's work illuminates the tensions between the local and global historical imaginaries of Jews, which often have very little to do with any actual Jewish populations. What is created through these performances is something quite different than cultural or historical realness; instead a projection of 'the host culture's' desires, anxieties, fears, and prejudices are displayed. Adding weight to this investigation, many of the host communities that Salamensky studies 
are places in which there was once a vibrant Jewish community that was either forcefully removed or eradicated.

The flip-side of this process occurs when evidence about the past does not match our preconceived forms of knowledge; when discoveries about the past are not "mimetic," when they do not mirror memories of other events, they can be called into question. This scenario is brought forth in this issue by Rachel Cyr's discussion of the absence of forensic evidence in Kosovo. When memories are not mimetic, what happens to the practice of witnessing? What happens to the ethics of memory? What happens when a globalized Holocaust memory becomes a screen memory - the memory for what genocide looks like? In the Kosovo example, as presented by Cyr, the absence of massive quantities of mass graves called into question, for some, the depth of the atrocity. Cyr's research brings up another important intervention in the thinking of screen memories: the screen of nothingness. What if the forensic evidence is lacking, or looks differently than expected, as is the case with regard to the mass atrocities committed in Kosovo? What problems does "absence" create for truth claims and gaining justice after atrocities are committed? Cyr uses the paradigm of the "empty tomb" in order to articulate the problems of forensic evidence and truth claims.

\section{Memory Regimes}

With their concept of "regimes of memory", Radstone and Hodgkin (2003) have built on the Foucauldian notion of power-knowledge, where memories are, like all forms of knowing, products of the webs of power-knowledge, while also (reproducing) the power relations that spin those webs. They rightly addle the foundations on which the simple notion of remembering as liberation stand, a mantra that echoes through the Venn diagram of memory studies, trauma studies, and even psychoanalysis. Remembering is not always the golden key that opens the trauma-memory cage, releasing its captives to healthier lives, forgiveness, truth, and/or reconciliation with the past.

That being said, "memory work" can be a liberating force that "undercuts assumptions about the transparency or the authenticity of what is remembered, treating it not as 'truth' but as evidence of a particular story: material for interpretation, to be interrogated, mined for its meanings, and possibilities" (Kuhn 2000, p. 186). Such questioning of evidence and truth claims is raised in Laliv Melamed's conversation with filmmaker Yael Hersonski. In A Film Unfinished (2010), Hersonski resuscitates an incomplete Nazi propaganda film that served for decades as a historical document of life in the Warsaw ghetto. By tracing what was left outside the film's frame, she dissects the ways in which a specific discourse of (Holocaust) memory is produced, while exposing the complex relationship between mechanisms of violence, power, and the cinematic apparatus. Hersonski's framing allows a different understanding of film as a historical document while shifting our focus from what is shown to what is cut. By looking closely at the cinematic mechanisms of editing and sound mixing some tracing of what was initially perceived as absent might be possible. We suggest that $A$ Film Unfinished is a screened memory. The films within a film demonstrate the multidirectional and multidimensional structure of memory: the blockages, contestation, circulation of images, and the constant reframing that takes place between the multiple screens.

Memory practices, like all cultural practices, are shaped by the fields of power in which they are produced and enacted: they reflect the interests and politics of the present. This becomes apparent whether we place the Jewish museum in Berlin in the context of current discourses about multiculturalism in Germany (Sodaro), the Danish incorporation of its colonial past into public history in the context of increasing pressure from the former 
colonies (Andersen), or discourses about a European ethics of memory in the context of Turkey's bid for EU membership (Nienass).

The encounter between present and past understood as a process defined by conflicts, but also aporias, runs through all articles in this issue. Both the impossibility to fully recover and redeem the past and the impossibility to fully depart from it act as painful but powerful reminders that talk about "closure" is often, if not always, premature. Like the film discussed by Hersonski and Melamed, the past remains 'unfinished' and can consequently be unraveled again and again. Like the figure of the Jew in Spanish communities of memory, the past itself is "a creature of the ether, everywhere but nowhere" (Salamensky 2013), impossible to grasp fully, and equally impossible to avoid. As Melamed points out in her interview, in our present encounter with the Warsaw ghetto through incomplete memory fragments, we are asked to pause and to understand, only to realize that we understand close to nothing.

This "nervous circulation of the past" (Bach 2013) raises political and ethical questions alike. In Bach's article, the notion of the labor of the negative eschews all pretensions of "mastering" or "overcoming" trauma, but instead focuses on an engagement with the past (and its material manifestations) that constantly makes absences present and implicates the self in the experiences of the other; it negates any clear-cut opposition between past and present or between self and other. Bach also warns that this empathy can break down distinctions between perpetrator and victim too easily and create false comfort where it is least expected.

Faced with the ethical choices in the light of "negative evidence", Cyr draws on the French philosopher Alain Badiou to suggest "what thought requires is not another gesture of negation but rather some kind of affirmation that would constitute a form of action" (Cyr 2013), a form of action based on the very experience of absence. Yet this option too is accompanied by a warning, since Badiou engages in "a risky wager where ethical experience affirms a truth that is completely indifferent to many of the terms of reference that ground our contemporary ethics of memory" (Cyr 2013).

\section{Emerging and Emergent Possibilities in Rethinking Screen Memory}

The contributors to the special issue arrive at the question of screen memory and screened memories from a variety of disciplines across the social sciences and humanities, such as performance studies, cultural studies, political theory, anthropology, and sociology. Informed by comparative historical and cultural analysis, critical theory, textual analysis, and ethnographic research, the special issue seeks to carve out a study of screen memory that takes into account competing truth claims about the past and seeks to question the simple adoption of a theory of globalized memory, as well as its outright rejection. In the following articles, what is being recalled by memory is intimately linked with the politics of sites of memory.

The authors mobilize the concept of screen memory from immaterial content to lived spaces and material objects. In so doing, they practice a material reading of history and culture, exposing and negotiating the implications of modes of display, systems of exhibition and distribution, as well as the role of objects or bodies to incorporate or house certain memories. We examine the concept of screen memory through the possibility of connection, rather than only seeing the competition of global memories. We argue that a re-invigorated concept of screen memory can give us new ways to think about multidirectional memory in a contemporary context. Ultimately, the special issue raises the question of displacement and resistance of memory through the concept of screens by asking how some transnational or 
"global" memories can become evasive screen memories in societies for whom other traumas are more prominent, or to different generations for whom recent events maybe more defining. The concept of screen memory shows how memories of global traumas may displace local traumas, but can also be productive for the creation of counter-memory. Unquestionably, there are "memory regimes", as defined by Radstone and Hodgkin, but within those regimes there are unruly memories and those who resist the memory imperatives to which they are pushed towards. We seek to trouble notions of knowledge production (and also memory production) through a focus on everyday objects, popular culture, and social practices. We seek to raise questions of material evidence and lived spaces to illuminate the peregrinations of memory across borders and boundaries, time zones and generations. We propose that an interrogation of the relationship between screens and memory, as evidenced by the papers included in this issue, can provide for such a turn.

\section{References}

Assman, J. (1995). Collective memory and cultural identity. New German Critique, 65, 125-133.

Bach, J. (2013). Memory Landscapes and the Labor of the Negative in Berlin. International Journal of Politics, Culture, and Society. doi:10.1007/s10767-013-9134-y.

Benjamin, W. (2003). On the concept of history. In Selected writings: volume 4, 1938-1940 (pp. 389-400). Cambridge: Belknap Press.

Cyr, R. E. (2013). Testifying Absence in the Era of Forensic Testimony. International Journal of Politics, Culture, and Society. doi:10.1007/s10767-013-9140-0.

Derrida, J. (1996). Archive fever: a freudian impression. Chicago, IL: Chicago University Press.

Freud, S. [1901] (1959). Screen memories. In: Collected papers III. New York: Basic Books.

Giddens, A. (1990). The consequences of modernity. Stanford: Stanford University Press.

Kammen, M. (1991). The mystic chords of memory: the transformation of tradition in American culture. New York: Vintage.

Kuhn, A. (2000). A journey through memory. In S. Radstone (Ed.), Memory and methodology. Oxford, UK: Berg.

Müller, J.-W. (2007). Europäische Erinnerungspolitik Revisited. Eurozine, October. http://www.eurozine.com/ articles/2007-10-18-jwmuller-de.html. Accessed: 1 March 2011

Nienass, B. (2013). Postnational Relations to the Past: A "European Ethics of Memory"? International Journal of Politics, Culture, and Society. doi:10.1007/s10767-013-9137-8.

Olick, J. (2007). The politics of regret: on collective memory and historical responsibility. New York: Routledge.

Olick, J. (2008). The ciphered transits of collective memory: Neo-Freudian impressions. Social Research, $75.1,1-22$.

Radstone, S., \& Hodgkin, K. (Eds.). (2003). Regimes of memory. Oxford: Routledge.

Rothberg, M. (2008). Multidirectional memory: remembering the holocaust in an age of decolonization. Stanford: Stanford University Press.

Salamensky, S. I. (2013). Culture, Memory, Context: Reenactments of Traumatic Histories in Europe and Eurasia. International Journal of Politics, Culture, and Society. doi:10.1007/s10767-013-9138-7.

Sodaro, A. (2013). Memory, History and Nostalgia in Berlin's Jewish Museum. International Journal of Politics, Culture, and Society. doi:10.1007/s10767-013-9139-6.

Stewart, K. (1996). A space on the side of the road: cultural poetics in an 'other' America. Princeton: Princeton University Press. 